\title{
TOPOGRAPHIC INFLUENCES ON THE POPULATION PERSISTENCE OF A TERTIARY RELICT DECIDUOUS TREE EMMENOPTERYS HENRYI OLIV. ON MT. TIANMU, EASTERN CHINA
}

\author{
SHANG, K. K. ${ }^{*}-$ CHEN, B. ${ }^{2}-$ ZHANG, X. J. ${ }^{3}-$ DA, L. J. ${ }^{3}$ \\ ${ }^{1}$ Shanghai Chenshan Plant Science Research Center, the Chinese Academy of Science, \\ Shanghai Chenshan Botanical Garden, Shanghai, China \\ ${ }^{2}$ School of Biological and Environmental Sciences, Hangzhou Normal University, China \\ ${ }^{3}$ School of Ecological and Environmental Sciences, East China Normal University, Shanghai, \\ China \\ (phone: +86-21-37792288; fax: +86-21-6765-7811) \\ *Corresponding author \\ e-mail: shangkankan@163.com; phone: +86-13-611-791-939; fax:+86-21-6765-7811
}

(Received $2^{\text {nd }}$ Mar 2020; accepted $10^{\text {th }}$ Jul 2020)

\begin{abstract}
Mt. Tianmu is one of the most important refugia of Tertiary relict plant taxa in Eastern China. We analyzed the habitat characteristics, community structure, demographic structure, and production methods of Tertiary relict deciduous forests at $1,100 \mathrm{~m}$ on Mt Tianmu $(1,506 \mathrm{~m})$, Zhejiang province, China. Emmenopterys henryi mostly occurred in unstable habitats with gap-formation or landslides, and these populations showed a sporadic regeneration pattern. E. henryi colonized and established at unstable sites by abundant wind-dispersed seeds. After colonization, E. henryi persisted for a long time and dominated in the canopy layer and even reached emergent layer due to its long lifespan and vegetative reproduction capability. It could thus be regarded as an undifferentiated climax pioneering species with an ' $r$-selected' life history that produced abundant minute seeds and experienced intermittent recruitment and often became pioneer species of secondary succession after moderate disturbance. Here, we discussed conservation strategies for Tertiary relict deciduous trees as climax pioneering species that accounted for the peculiarity of their habitat and population structure in broad-leaved forests.
\end{abstract}

Keywords: habitat instability, root sucker, population structure, reproduction methods, regeneration strategy

\section{Introduction}

Tertiary relict floras contain survivors from plant communities that were distributed throughout a large part of the Northern Hemisphere during much of the Tertiary (i.e. 65-15 million years ago (Ma)) (Milne and Abbott, 2002). They are now mainly restricted to warm humid areas (refugia) in southeastern and western North America, East Asia and southwest Eurasia (Milne and Abbott, 2002; Hampe and Arroyo, 2002). A number of deciduous broad-leaved ancient genera, considered to be Tertiary relicts, are found today in subtropical broad-leaved forests of China, such as Davidia involucrate, Tetracentron sinense, Cercidiphyllum japonicum var. sinense, Euptelea pleiospermum, Ginkgo biloba, Cyclocrya paliurus, Emmenopterys henryi, Tapiscia sinensis, Fortunearia sinensis etc. (Del Tredici, 1992; López-pujol et al., 2006; Gong et al., 2008; Wei et al., 2010; Wu et al., 2018). The current populations of these trees are very small and they usually coexist with other evergreen, deciduous and coniferous trees at relatively restricted ranges (Gong et al., 2008; Wu et al., 2018). During the 
Quaternary glaciations, these ancient species experience severely reduced regeneration and survived while most other members of their group were wiped out (Tzedakis et al., 2002; Shen et al., 2002; Tang et al., 2011; Qian et al., 2016). A majority of these species are globally threatened now (López-Pujol et al., 2006). How these relict species survive and persist under current climate conditions or those of rapid climate change and frequent human activities became an important topic for rare and endangered species conservation (Calleja et al., 2009).

Emmenopterys henryi Oliv, belonging to the Rubiaceae family, is an endangered deciduous tree endemic to China (Zhang, 2016). It is characterized by a long lifespan, intermittent flowering with 2-4 year intervals, production of abundant wind-dispersed minute seeds (0.3-0.6 g per 1000 grains) and reduce competitive ability with other deciduous pioneer tree species and evergreen tree species during the juvenile stage (Wang et al., 2002). It is of ancient origin, a relic of the paleotropical flora of the Cretaceous Period, Mesozoic Era, and is considered valuable both for its unique position in the flora of China and in the systematic evolution of the Rubiaceae. E. henryi primarily occurs in ravines and mountain valleys at altitudes of $400-1400 \mathrm{~m}$ in southwestern China and the Yangtze River Valley. Populations of E. henryi have been affected by habitat destruction and over-exploitation in the wild. It has been listed as a threatened species within China due to its lower regeneration. Previous researches mainly focused on chemical components, seed physiology, community structure and genetic structure (Ma and He, 1989; Zhang et al., 2007; Li and Jin, 2008; Guo et al., 2017a,b; Ma et al., 2019). Kang et al. (2007), Guo et al. (2017a) and Ma et al. (2019) also reported that $E$. henryi regenerates through both sexual and asexual modes, but scientific analysis of its regeneration mechanism along the topographic gradients, has not been described. Further studies may be necessary to evaluate potential adaptation of populations to local environmental conditions.

Therefore, this paper focuses on: (1) community structure, distribution pattern and demographic structure of main trees, and (2) the production methods of $E$. henryi population along the topographic gradients, to reveal that how they persisted as related to habitat. The inhabiting habitats, production methods and regeneration strategy of other similar relict trees have been compared to determine whether these relict trees have similar peculiarity for persistence at relatively restricted ranges.

\section{Materials and Methods}

\section{Study site}

The study was conducted at the Mt. Tianmu Nature Reserve (30 $18^{\prime} 30^{\prime \prime}$ $30^{\circ} 21^{\prime} 37^{\prime}$ 'N, 119 $24^{\prime} 11^{\prime}$ ' 119 27'11' E, Zhejiang Province, P. R. China), which is one of the most famous protected areas in China and throughout the world due to its remarkable number of large, rare and endangered plants. The foothill region is located at 300-350 $\mathrm{m}$ a.s.1., which gradually rises to $1,056 \mathrm{~m}$ a.s.1. Mt. Tianmu is characterized by a subtropical humid climate (Qian et al., 2002). According to records from weather stations at Chanyuan Temple (350 m a.s.1.) near the base and Xianrending (1,506 $\mathrm{m}$ a.s.l.) near the summit of Mt. Tianmu from 1987 to 1996, the average annual temperature is $14.5^{\circ} \mathrm{C}$ and $9.0^{\circ} \mathrm{C}$, and the average annual precipitation is $1,739 \mathrm{~mm}$ and 1,751 $\mathrm{mm}$ for Chanyuan Temple and Xianrending, respectively (Da et al., 2009). Because the stratum was affected by tectonic movements and volcanic activity, the study area is made up of steep slopes and irregular terrain, especially many complex 
landscape structures between $900 \mathrm{~m}$ and 1,100 m a.s.1. $90 \%$ of this area is covered with volcanic rock, and the zonal soils are comprised of red soils (below $600 \mathrm{~m}$ a.s.1.), yellow soils (600-1,200 m a.s.1.) and brown yellow soils (above 1,200 m a.s.1.) (Xia, 2004).

\section{Data collection}

The population size and distribution region of E. henryi on Mt. Tianmu is small by our survey on July to August 2010, which mainly concentrated on the mid-altitude region from $900 \mathrm{~m}$ a.s.l. to 1,200 $\mathrm{m}$ a.s.l. They were mainly distributed at roadsides, and in valleys, gravel mounds, cliffs, etc. Besides, we also founded that a few of seedlings and saplings of $E$. henryi grow on fallen log of the gap-maker. We established plots by patch sampling in twelve locations representing three micro-topographies (Table 1). Plot 1-4 (total 1,600 $\mathrm{m}^{2}$ ) was established in an old canopy gaps surrounded by old-growth Cryptomeria fortunei. These plots were located on hollow head with an average $20.0^{\circ}$ incline. Plots 5-8 (total $1,600 \mathrm{~m}^{2}$ ) were established in flood terrace with an average $16.0^{\circ}$ incline. Plot 9-12 (total $1,400 \mathrm{~m}^{2}$ ) was established in river bed on a seasonally active channel with a mean $23.8^{\circ}$ incline. A more detailed description of these three microtopographies was shown in Table 2 by surveyed.

Table 1. The geological properties of 12 sampling plots

\begin{tabular}{c|c|c|c|c|c|c}
\hline Plot & GPS position & Microtopography & $\begin{array}{c}\text { Sampling } \\
\text { area }\left(\mathbf{m}^{2}\right)\end{array}$ & $\begin{array}{c}\text { Altitude } \\
(\mathbf{m})\end{array}$ & $\begin{array}{c}\text { Slope } \\
\left({ }^{\circ}\right)\end{array}$ & Aspect \\
\hline 1 & $30^{\circ} 20^{\prime} 18.4^{\prime \prime}, 119^{\circ} 25^{\prime} 44.8^{\prime \prime}$ & Hollow head & 400 & 1062 & 15 & S30E \\
2 & $30^{\circ} 20^{\prime} 32.3^{\prime \prime}, 119^{\circ} 26^{\prime} 06.8^{\prime \prime}$ & Hollow head & 400 & 1113 & 10 & S65W \\
3 & $30^{\circ} 19^{\prime} 52.0^{\prime \prime}, 119^{\circ} 25^{\prime} 45.6^{\prime \prime}$ & Hollow head & 400 & 1000 & 30 & NE45 \\
4 & $30^{\circ} 20^{\prime} 25.5^{\prime \prime}, 119^{\circ} 25^{\prime} 59.5^{\prime \prime}$ & Hollow head & 400 & 980 & 25 & S15E \\
5 & $30^{\circ} 20^{\prime} 29.8^{\prime \prime}, 119^{\circ} 26^{\prime} 05.6^{\prime \prime}$ & Flood terrace & 400 & 1097 & 10 & N10W \\
6 & $30^{\circ} 20^{\prime} 29.8^{\prime \prime}, 119^{\circ} 25^{\prime} 58.4^{\prime \prime}$ & Flood terrace & 400 & 1080 & 14 & S30W \\
7 & $30^{\circ} 21^{\prime} 33.5^{\prime \prime}, 119^{\circ} 25^{\prime} 21.1^{\prime \prime}$ & Flood terrace & 400 & 1050 & 15 & NE30 \\
8 & $30^{\circ} 20^{\prime} 20.8^{\prime \prime}, 119^{\circ} 25^{\prime} 48.2^{\prime \prime}$ & Flood terrace & 400 & 1020 & 25 & S79E \\
9 & $30^{\circ} 20^{\prime} 27.5^{\prime \prime}, 119^{\circ} 25^{\prime} 59.0^{\prime \prime}$ & River bed & 400 & 1064 & 20 & S15E \\
10 & $30^{\circ} 21^{\prime} 33.5^{\prime \prime}, 119^{\circ} 25^{\prime} 33.7^{\prime \prime}$ & River bed & 400 & 1050 & 23 & NE50 \\
11 & $30^{\circ} 19^{\prime} 54.3^{\prime \prime}, 119^{\circ} 25^{\prime} 51.4^{\prime \prime}$ & River bed & 400 & 856 & 30 & NE45 \\
12 & $30^{\circ} 20^{\prime} 18.4^{\prime \prime}, 119^{\circ} 25^{\prime} 47.8^{\prime \prime}$ & River bed & 200 & 975 & 22 & S74E \\
\hline
\end{tabular}

Table 2. The characteristics of three different microtopographies

\begin{tabular}{c|c|c|c}
\hline Habitat & Hollow head & Flood terrace & River bed \\
\hline Situation & Upper gentle slope & Lower gentle Slope & Middle gentle slope \\
Litter cover & High & Low-high & Low \\
Soil depth & Deep & Medium & Shallow \\
Soil humidity & Low & High & Low \\
Disturbance type & Soil erosion & Soil erosion & Soil erosion \\
Physical stability & Relatively stable & Moderately unstable & Unstable \\
\hline
\end{tabular}

Because the canopy layer forms at heights above $8 \mathrm{~m}$ in these plots, we expressed the strata of the forest as follows: tree layer, $8 \mathrm{~m}<$ height $(\mathrm{H})$; subtree layer, $4 \mathrm{~m} \leq \mathrm{H} \leq 8 \mathrm{~m}$; shrub layer, $1.5 \mathrm{~m} \leq \mathrm{H}<4 \mathrm{~m}$; sapling, $0.5 \mathrm{~m} \leq \mathrm{H}<1.5 \mathrm{~m}$; seedlings, $\mathrm{H}<0.5 \mathrm{~m}$. In each whole plots, we recorded the species, measured the diameter at breast height $(1.5 \mathrm{~m}$ above ground; $\mathrm{DBH}$ ) and the height of trees $\geq 1.5 \mathrm{~m}$. The quantities and heights of seedlings and saplings of $E$. henryi were also identified and measured. 
The plantlets of $E$. henryi were classified into two types, true seedlings from seed-origin and root suckers from adventitious buds on lateral roots, identified by removing the litter and surface soil of lateral roots. Besides, individuals with own root systems in shrub or tree layer were also considered to be seed-orientated. Root suckers remained connected to parent tree for several years and could increase competitively and greater survival under adverse environmental conditions (Ky-Dembele et al., 2007; Beaudet and Messier, 2008).

\section{Data analysis}

The dominant species were identified by Ohsawa's dominance analysis method using the relative basal area (RBA) of each species. This analysis is based on the least deviation $(d)$ between the share obtained by a given species, as a percentage of the total basal area $\left(x_{i}\right)$, and its calculated share if all species were equally represented $\left(x^{\prime}\right)$ :

$$
d=1 / N\left\{\sum_{i \in T}\left(x_{i}-x^{\prime}\right)^{2}+\sum_{j \in U} x_{j}^{2}\right\}
$$

where $\mathrm{T}$ is the number of 'top species' in a given dominant-number-model, $\mathrm{U}$ is the number of remaining species, and $\mathrm{N}$ is the total number of species. For example, in a community dominated by single species, $x{ }^{\prime}=100 / \mathrm{T}$ (where $\mathrm{T}=1$ ), the top dominant's share is $100 \%$. If, however, two species share dominance, the top two dominants share $50 \%$, or if there are three co-dominants, $33.3 \%$, and so on. Species diversity was expressed by Shannon-Wiener Index.

For determining whether these Tertiary relict trees have similar regeneration mechanisms, more or less complete information on the inhabiting habitat, seed mass per 1000 grains, dispersal agent and production methods was available from literatures (Shang et al., 2016). The types of vegetative reproduction were clarified into five types. Seedling sprout means a plantlet of seed origin that was affected by shoot dieback, but re-sprouted from the root collar of the seedling; root sucker means a plantlet arising vertically from superficial lateral root; coppice means a plantlet arising from stumps of cut mature tree in response to logging or non-logging disturbances and which root diameter exceeds $10 \mathrm{~cm}$; water sprout means a plantlet developed from the base of alive mature tree; layer means a plantlet developed from low hanging lateral branch (Ky-Dembele et al., 2007).

\section{Results}

\section{Floristic characteristics}

Within a total of nearly $4,600 \mathrm{~m}^{2}$ plots in all habitats, 69 woody species belonging to 54 genera and 37 families were recorded (Appendix A). The tree life-forms were deciduous broad-leaved, evergreen broad-leaved, deciduous coniferous and evergreen coniferous, but only 9 species were evergreen. Of the deciduous species, 3 genera (Pseudolarix, Emmenopterys and Cyclocarya) were endemic to China, 7 genera (Kalopanax, Acanthopanax, Ehretia, Corylopsis, Deutzia, Dendrobenthamia and Stachyurus) were endemic to East Asia. Of the evergreen trees, one genus (Cunninghamia) was endemic to China, 3 genera (Cryptomeria, Lithocarpus and Orixa) were endemic to East Asia. Northern temperate deciduous broad-leaved genera such as 
Petrocarya, Acer and Viburnum, pantropic genera and old-world temperate genera were also appeared. Besides, many relict species such as E. henryi, Cyclocarya paliurus, Magnolia cylindrical, Pseudolarix amabilis were co-existed in the community. Hence, the ancient and complexity of community were remarkable that with so many plants of diverse geographic distributions as well as Tertiary relicts.

$E$. henryi could establish them on different microtopography along habitat instability and become a dominant. In the hollow head with relatively stable, was co-dominated by $P$. amabilis, $C$. fortunei and $E$. henryi; the relative dominance value of $E$. henryi was 15.2-67.6\%. In the flood terrace with moderately unstable, C. fortunei, E. henryi and $P$. amabilis were co-dominant; the relative dominance value of $E$. henryi was 23.7-57.2\%. In the river bed, E. henryi as the first dominant was co-dominated with $C$. fortunei and the relative dominance value reached to $41.9-97.0 \%$.

\section{Height-class distribution with increasing habitat instability}

The height-class frequency distribution of all woody species is shown in Fig. 1. In the hollow head, the number of evergreen individuals was more than deciduous and the ratio of evergreen/deciduous was 1.16. Evergreen species such as Cyclobalanopsis gracilis, Lithocarpus harlandii and $C$. fortune were found in the shrub, subcanopy and canopy layers. Besides, deciduous trees $E$. henryi and C. paliurus were also found in all three layers, and the former even reaching the emergent layer (above the canopy, more than $20 \mathrm{~m}$ ). In the flood terrace, the number of evergreen individuals was decreased, and the ratio of evergreen/deciduous reached to 0.48 . They mainly appeared in shrub and subcanopy layer (below $10 \mathrm{~m}$ ) while E. henryi were found in all layers. In the river bed, although $C$. fortunei could reach the emergent layer, evergreen individuals including $L$. harlandii and $C$. fortune $i$ were rare and mainly confined to the shrub layers. The canopy, subcanopy and shrub layers of the forest were occupied by E. henryi and other deciduous trees such as Alangium chinense and Bothrocaryum controversum.

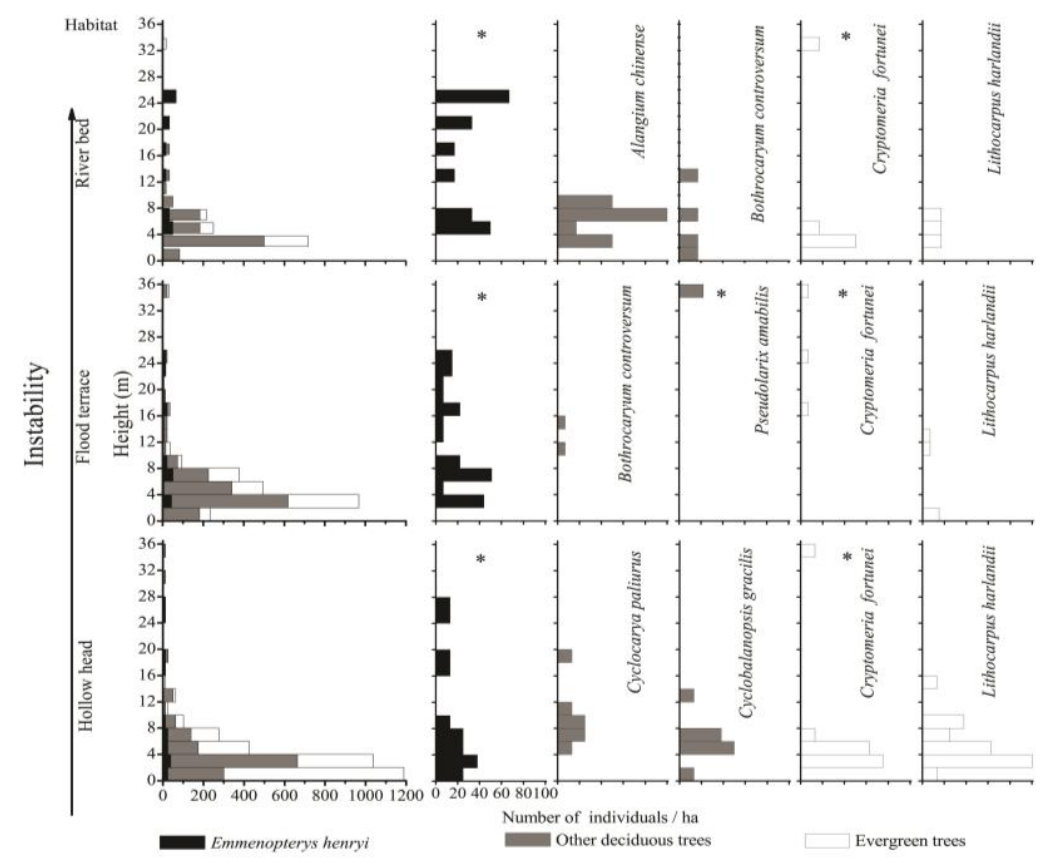

Figure 1. Height-class frequency distribution of all individuals and main populations with increasing. Dominant species are indicted by an asterisk 


\section{Population structure with increasing habitat instability}

These communities include unimodal, sporadic and L types of size-class frequency distribution (Fig. 2). The unimodal type, with a single peak in the intermediate or large size-classes, and fewer if any individuals in small size-classes, suggests a weak regeneration pattern. Evergreen trees L. harlandii, C. gracilis and Cunninghamia lanceolata located on valley and C. fortunei appeared in all three habitats were of this type. The sporadic type, with more than one peak in the size-classes, indicates the possibility of good regeneration. E. henryi occurred in all three microtopography were of this sporadic type, but the number of populations decreased along habitat instability. Active regeneration is suggested by the $L$ type having the highest frequency in small DBH classes. In hollow head and flood terrace habitats, evergreen trees $L$. harlandii, C. gracilis and $C$. lanceolata was of this type, indicating that these evergreen canopy species were suppressed by the dominant deciduous species but their populations could develop.

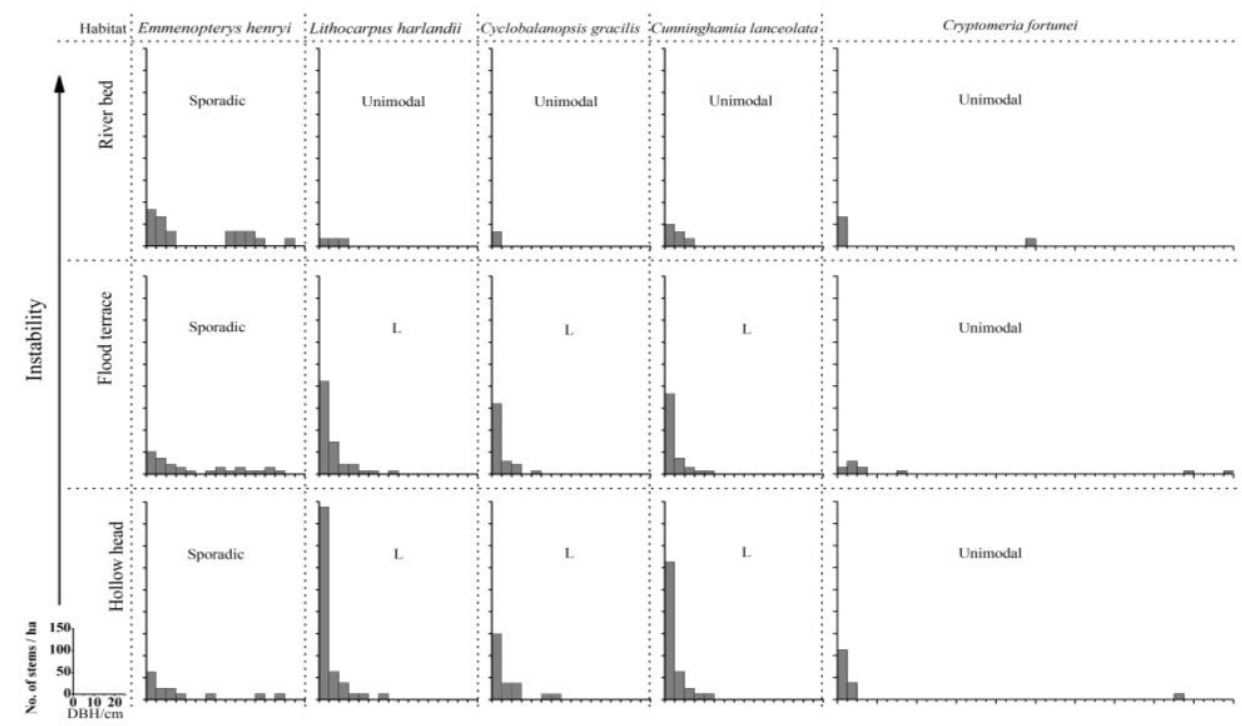

Figure 2. Size-class frequency distribution for the E. henryi population and main evergreen tree with increasing habitat instability

\section{Sprouts ratio of E. henryi population at different habitat}

Although the reproduction of $E$. henryi was by means of seeds at many habitats, such as gravel mound, canopy gap and fallen-log by our investigation, the resprouter by root sucker were also abundant at hollow head and river bed habitat (Fig. 3). In the hollow head, 23 stems (including 14 seedlings and 9 saplings) were found to regenerate successfully from root suckers and 9 individuals were true seedlings or assumable seed-orientated trees. And 2 of these individuals were located on fallen-log. In the river bed, 6 stems originated from root suckers and 6 individuals were true or assumable seed-orientated trees. The suckering stems accounted for $72 \%$ of all stems in the hollow head, while $50 \%$ in river bed. 


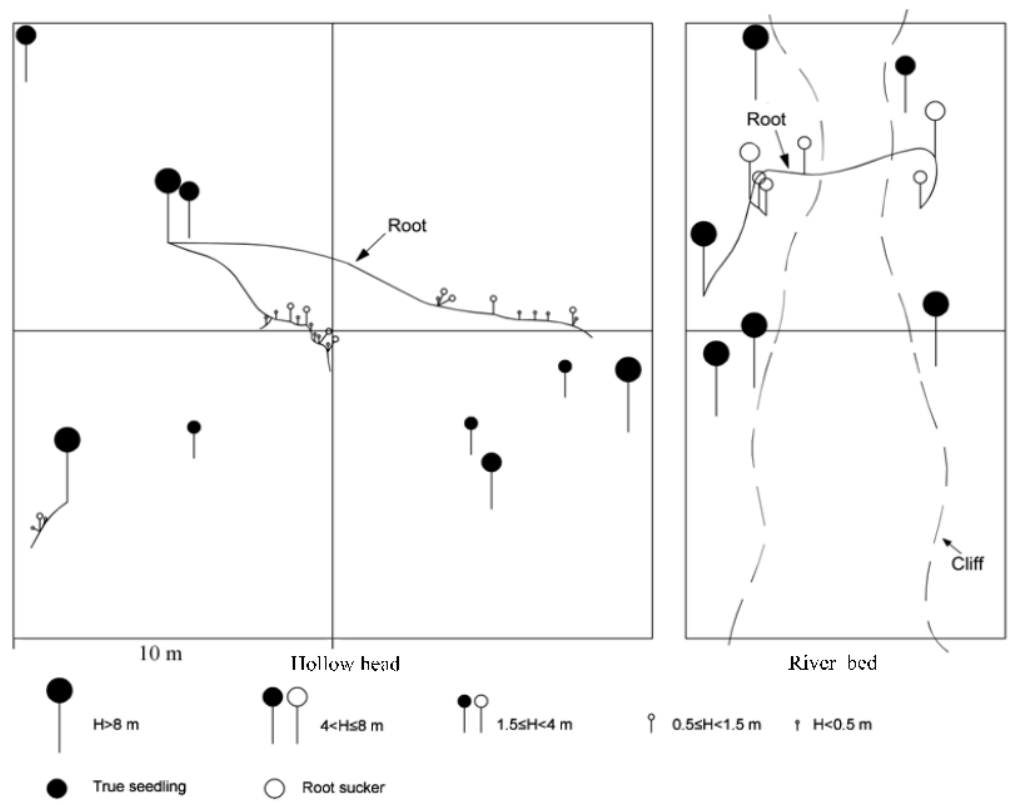

Figure 3. Vegetative mode of E. henryi population in hollow head and river bed

\section{Discussion}

Reproductive strategy and population persistence of $E$. henryi in relation to microtopography

The distribution of E. henryi on Mt. Tianmu was primarily at unstable habitats, such as hollow head valleys, flood terrace, fallen logs and gravel-mounds. This was similar to other Tertiary relict species, such as Euptelea polyandra in warm-temperature forest of Japan (Sakai and Ohsawa, 1993), Euptelea pleiospermum, Cercidiphyllum japonicum and Davidia involucrata in subtropical evergreen broad-leaved forests of western China (Tang and Ohsawa, 2002; Wei et al., 2010; Wu et al., 2018), Frangula alnus subsp. Baetica and Prunus lusitanica in Iberian Peninsula of Spain (Hampe and Arroyo, 2002; Calleja et al., 2009; Pardo et al., 2018). All these trees seem to require very particular unstable habitats where competition from other trees is limited.

At those unstable habitats, the deciduous pioneer tree E. henryi could colonize firstly by mean of abundant minute seeds production (0.3-0.6 g per 1,000 grains) after moderate disturbance (Kang et al., 2007; Shang et al., 2016). Their populations experienced intermittent recruitment as shown by the sporadic type of stem-diameter class frequency distribution, while evergreen trees regenerated more weakly along habitat instability (Fig. 2). At hollow head and flood terrace habitat with lower unstable, $E$. henryi can dominate in the canopy layer and even reach the emergent layer due to its long life span (Fig. 1; Appendix A). When these habitats become more stable, the evergreen trees $L$. harlandii, $C$. gracilis and $C$. lanceolata may become dominants according to the regeneration pattern (Fig. 2). At river bed habitat with frequent landslide, E. henryi could recruit well due to the possibility of good regeneration while other evergreen trees were not (Fig. 2). Here, the E. henryi dominated forest in the river bed on Mt Tianmu could be regarded as a topographic climax phenomenon formed in an area of landslide disturbances. 
The results of this investigation showed that asexual reproduction resprouted by long-distance root (root sucker) was the important mechanism of seedling recruitment of E. henryi population (Fig 3, Guo et al., 2017a). The suckering stems accounted for $72 \%$ of all plantlets in hollow head compared to $50 \%$ in river bed. This is because although $E$. henryi can colonize at different habitats by the active production of seeds, the seed germination and seedling establishment are influenced by environmental filtering (Zhang et al., 2007; Guo et al., 2017b). The seed germination and seedling recruitment of $E$. henryi at current conditions are hampered by the thick layer of leaf litter in gentle slope habitat except for fallen-log, which agrees with previous findings that seedlings produced by small seeds may be unable to emerge in sites with thicker litter layers (Carlton and Bazzaz, 1998; Castro et al., 1999). After the stage of seedling-establishments, a light-demanding deciduous pioneer tree, E. henryi can not compete with modern deciduous pioneer tree species and evergreen tree species due to its reduced competitive ability during the juvenile stage (Zhang et al., 2007; Pulido et al., 2008). On the other hand, resprouts arising from vegetative reproduction grow faster than newly established seedlings due to their well-established root system (Ky-Dembele et al., 2007), providing better resistance to stress in their first years (Deiller et al., 2003), and a stronger competitive advantage (Beaudet and Messier, 2008). It can be considered that root suckers probably contribute to the survival and maintenance of $E$. henryi population by reducing vulnerability to severe disturbance and recruitment failure (Guo et al., 2017a).

Ohsawa (1991) have suggested that most sporadic type species who experienced intermittent recruitment can be regarded as a kind of pioneers in the climax forests and called 'undifferentiated canopy components' that between a nomadic pioneer and a climax species. E. henryi populations have experienced intermittent recruitment in hollow head and flood terrace habitat with relatively stable (Fig. 2). Moreover, $E$. henryi is a deciduous pioneer tree that characterized by a long life span, intermittent flowering with 2-4 year intervals, and production of abundant wind-dispersed minute seeds (0.3-0.6 g per 1,000 grains). Thus we suggested that $E$. henryi can be regarded as an undifferentiated climax pioneering species with an 'r-selected' life history.

\section{Persistence mechanism of Tertiary relict deciduous trees as climax pioneering species}

A large number of deciduous broad-leaved trees of ancient genera, considered to be Tertiary relicts, occurred in the mid-altitude region of subtropical mountains (Table 2; Shang et al., 2016). The Tertiary relict trees seem to require very particular unstable habitats that mainly distributed on valley, forest edges, steep slopes and stream banks (Table 3). This is probably due to the importance of differential growth, differential survival and differential dispersal of species as well as its evolutionary factor (Pullio, 2008; Qian et al., 2016).

Since the Quaternary era, the distribution, population size and regeneration capacity of many Tertiary relict plant species has changed greatly (Tzedakis, 2002; Calleja et al., 2009; Zhang et al., 2016). Owing to their reduced competitive ability with modern floras and their ecophysiology (Pulido et al., 2008), these species need to colonize on 'safe sites' where competition from other species is limited (Tang and Ohsawa, 2002). The environmental stochasticity in unstable habitats could provide more opportunity for regeneration of seed-orientated species and decrease interspecific competition (García, 2003). Therefore, Tertiary relict trees would recruitment intermittent by abundant minute wind-dispersal seeds (Table 2; Zhang et al., 2007; Li et al., 2008). 
Table 3. Known distribution habitat, vegetation regeneration strategies, and dispersal agent of the main relict deciduous tree in China's subtropical forests

\begin{tabular}{c|c|c|c|c}
\hline Relict deciduous trees & Main habitats & $\begin{array}{c}\text { Seed mass } \\
(\mathbf{g} / \mathbf{1 , 0 0 0})\end{array}$ & $\begin{array}{c}\text { Dispersal } \\
\text { agent }\end{array}$ & $\begin{array}{c}\text { Vegetative } \\
\text { mode }\end{array}$ \\
\hline Annamocarya sinensis & Valley, stream bank & $9000-13000$ & Mammals & $\begin{array}{c}\text { Water sprout; } \\
\text { Coppice }\end{array}$ \\
Bretschneidera sinensis & Humidity valley, stream bank & $715-780$ & Wind & Coppice \\
Camptotheca acuminata & Stream bank, forest edge & $34-45$ & Wind & Water sprout \\
Cercidiphyllum japonicum & Steep slope, valley, stream bank & $0.75-0.9$ & Wind & Water sprout \\
Cyclocarya paliurus & Steep slope, creek valley, forest & 200 & Wind & Water sprout \\
& edge & & & Water sprout; \\
Davida involucrata & Steep slope, ravine & $3400-5500$ & Mammals & Coppice \\
& Valley,dry ravines & $58-130$ & Wind & Root sucker; \\
Eucommia ulmoides & Steep slope & $125-220$ & Birds & Water sprout \\
Halesia macgregorii & Valley, stream bank & $4.3-6.4$ & Wind & Water sprout \\
Liquidambar formosana & Valley & $22-35$ & Wind & Coppice \\
Liriodendron chinense & Valley, stream,steep slope & $125-240$ & Birds & Water sprout \\
Nyssa sinensis & Foothill, forest edge, river bed & $21-28$ & Wind & Water sprout \\
Pteroceltis tatarinowii & Valley, hillside, rocky ravine & $0.1-0.15$ & Wind & Coppice \\
Tetracentron sinensis & Valn
\end{tabular}

Note: Sources: Shang et al., 2016

On the other hand, Tertiary relict trees could sprout new shoots in subtropical area of China, including water sprouts, coppices, and root suckers (Table 2). It seems to allow the population to recruitment quickly after disturbance. This supplemental mechanism for population persistence is similar to that of E. henryi in our study, E. polyandra in Japan and Rhododendron ponticum in Mediterranean, which allocate more resources to sprouts than to reproduction by seeds (Sakai et al., 1995; Mejías et al., 2002).

These characteristics are coincident with the general tendency that the Tertiary relict deciduous trees survive and persist well in the unstable scree slopes where competition is not severe, but are unable to thrive in the stable habitats where competition is more rigorous (Tang and Ohsawa, 2002). Consequently, minute easily-dispersed seeds and seedling recruitment supplemented with vegetative reproduction seem to be most important reasons why Tertiary relict deciduous trees have been able to persist at a given site after frequent disturbance (Milne and Abbott, 2002).

\section{Conclusion}

Many of Tertiary relict deciduous trees regarded as an undifferentiated climax pioneering species with an 'r-selected' life history has very few individuals remaining. They are of high conservation concern due to their rarity and their phylogenetic uniqueness, and are therefore very important to China and the world. Responsible conservation efforts should aim to maintain present populations of these species and expand their distribution by creating new habitat. Firstly, restoration efforts should focus both on preserving habitats by protecting valley bottoms, stream habitats, and hollows, and also on preserving or restoring the natural disturbance regime. Secondly, we should prohibit salvage logging or clearing of fallen trees so that this wood can 
provide opportunities for the recruitment of seedlings. Thirdly, in order to maintain sufficient genetic variation in a small area, it is important to increase the population of true seedlings (i.e. not resprouts) through protection of seedlings and/or increasing the sowing density. Moreover, plantations could function as starting points for the natural restoration of extirpated populations in unstable habitats. These measures, together with effective legal protections against human disturbance, might help to improve the longterm persistence of Tertiary relict trees in subtropical area of China during future changes in climate.

Acknowledgments. This study was funded by the National Key Research and Development Projects (2016YFC050310203) and National Natural Science Foundation of China (31600343).

\section{REFERENCES}

[1] Beaudet, M., Messier, C. (2008): Beech regeneration of seed and root sucker origin: A comparison of morphology, growth, survival, and response to defoliation. - Forest Ecology and Management 255: 3659-3666.

[2] Calleja, J. A., Garzón, M. B., Ollero, H. S. (2009): A Quaternary perspective on the conservation prospects of the tertiary relict tree Prunus lusitanica L. - Journal of Biogeography 36: 487-498.

[3] Carlton, G. C., Bazzaz, F. A. (1998): Regeneration of three sympatric birch species on experimental hurricane blowdown microsites. - Ecology Monographs 68: 99-120.

[4] Castro, J., Gómez, J. M., García, D., Zamora, R., Hódar, J. A. (1999): Seed predation and dispersal in relict Scots pine forests in southern Spain. - Plant Ecology 145: 115-123.

[5] Da, L. J., Kang, M. M., Song, K., Shang, K. K., Yang, Y. C., Xia, A. M., Qi, Y. F. (2009): Altitudinal zonation of human-disturbed vegetation on Mt. Tianmu, eastern China. Ecological Research 24: 1287-1299.

[6] Deiller, A. F., Walter, J. M. N., Trémolières, M. (2003): Regeneration strategies in a temperate hardwood floodplain forest of the Upper Rhine: sexual versus vegetative reproduction of woody species. - Forest Ecology and Management 180: 215-225.

[7] Del Tredici, P. (1992): Natural regeneration of Ginkgo biloba from downward growing cotyledonary buds (Basal Chichi). - American Journal of Botany 19: 522-530.

[8] García, M. B. (2003): Demographic viability of a relict population of the critically endangered plant Borderea cbouardii. - Conservation Biology 17: 1672-1680.

[9] Gong, W., Chen, C., Dobes, C., Koch, M. A. (2008): Phylogeography of a living fossil: Pleistocene glaciations forced Ginkgo biloba L. (Ginkgoaceae) into two refuge areas in China with limited subsequent postglacial expansion. - Molecular Phylogenetics and Evolution 48: 1094-1105.

[10] Guo, L. J., Shao, X. H., Xue, P. P., Tian, Y. Q., Xiao, Z. P., Wu, Y. P. (2017a): Root sprouting ability and growth dynamics of the rootsuckers of Emmenopterys henryi, a rare and endangered plant endemic to China. - Forest Ecology and Management 389: 35-45.

[11] Guo, L. J., Xue, P. P., Li, M., Shao, X. H. (2017b): Seed bank and regeneration dynamics of Emmenopterys henyi population on the western side of Wuyi Mountain, South China. Journal of Forestry Research 28(5): 943-952.

[12] Hampe, A., Arroyo, J. (2002): Recruitment and regeneration in population of an endangered South Iberian Tertiary relict tree. - Biological Conservation 107: 263-271.

[13] Kang, H. J., Chen, Z. L., Liu, P., Hao, C. Y., Wei, F. M. (2007): The population structure and distribution pattern of Emmenopterys henryi in Dapanshan Natural Reserve of Zhejiang Province. - Acta Ecological Sinica 27: 389-396. (in Chinese with English abstract). 
[14] Ky-Dembele, C., Tigabu, M., Bayala, J., Ouedraogo, S. J., Oden, P. C. (2007): The relative importance of different regeneration mechanisms in a selectively cut savannawoodland in Burkina Faso, West Africa. - Forest Ecology and Management 243: 28-38.

[15] Li, J. M., Jin, Z. X. (2008): Genetic structure of endangered Emmenopterys henryi Oliv. based on ISSR polymorphism and implications for its conservation. - Genetica 133: 227234.

[16] López-Pujol, J., Zhang, F. M., Ge, S. (2006): Plant biodiversity in China: richly varied, endangered, and in need of conservation. - Biodiversity and Conservation 15: 3983-4026.

[17] Ma, Z. W., He, G. F. (1989): Studies on chemical constituents of Emmenopterys henryi Oliv. native to China. - Acta Botanica Sinica 31: 620-625. (in Chinese with English abstract)

[18] Ma, M. W., Wu, Y. H., Zhang, Y., Kang, H. J., Chen, Z. L., Liu, P. (2019): Sprouting as a survival strategy for non-coniferous trees: Relation to population structure and spatial pattern Emmenopterys henryi (Rubiales). - Acta Ecologica Sinica 29: 1-8.

[19] Mejías, J. A., Arroyo, J., Ojeda, F. (2002): Reproductive ecology of Rhododendron ponticum (Ericaceae) in relict Mediterranean populations. - Botanical Journal of the Linnean Society 140: 297-311.

[20] Milne, R. I., Abbott, R. J. (2002): The origin and evolution of Tertiary relict floras. Advances in Botanical Research 38: 281-314.

[21] Ohsawa, M. (1991): Structure comparison of tropical montane rain forests along latitudinal and altitudinal gradients in south and East Asia. - Vegetatio 97: 1-10.

[22] Pardo, A., Caceres, Y., Pulido, F. (2018): Rangewide determinants of population performance in Prunus lustitanica: Lessons for the contemporary conservation of a Tertiary relict tree. - Acta Oecologica 86: 42-48.

[23] Pulido, F., Valladares, F., Calleja, J. A. (2008): Tertiary relict trees in a Mediterranean climate: abiotic constraints on the persistence of Prunus lussitanica at the eroding edge of its range. - Journal of biogeography 35: 1425-1435.

[24] Qian, J. L., Lü, J., Tu, Q. P., Wang, S. M. (2002): Reconstruction of the climate in the Tianmu Mountain area, Zhejiang Province, in the last 160 years by $\delta 13 \mathrm{C}$ sequence of tree ring $\alpha$-cellulose. - Science in China (Series D) 45(5): 409-419.

[25] Qian, S. H., Yang, Y. C., Tang, C. Q., Momohara, A., Yi, S. R., Ohsawa, M. (2016): Effective conservation measures are needed for wild Cathaya argyrophylla populations in China: Insights from the population structure and regeneration characteristics. - Forest Ecology and Management 361: 358-367.

[26] Sakai, A., Ohsawa, M. (1993): Vegetation pattern and microtopography on a landslide scar of Mt Klyosumi, central Japan. - Ecological Research 8: 47-56.

[27] Sakai, A., Ohsawa, T., Ohsawa, M. (1995): Adaptive significance of sprouting of Euptelea polyandra, a deciduous tree growing on steep slopes with shallow soil. - Journal of Plant Research 108: 377-386.

[28] Shang, K. K., Song, K., Da, L. J. (2016): Ecology of relict Tertiary deciduous trees in subtropical China. - In: Box, E. O. (eds.) Vegetation structure and function at multiple spatial, temporal and conceptual scales. Springer, pp. 149-167.

[29] Shen, L., Chen, X. Y., Li, Y. Y. (2002): Glacial refugia and postglacial recolonization patterns of organism. - Acta Ecol Sinica 22: 1983-1989. (in Chinese with English abstract).

[30] Tang, C. Q., Ohsawa, M. (2002): Tertiary relic deciduous forests on a humid subtropical mountain, Mt. Emei, Sichuan, China. - Folia Geobotanica 37: 93-106.

[31] Tang, C. Q., Yang, Y. C., Ohsawa, M., Momohara, A., Hara, M., Cheng, S. L., Fan, S. H. (2011): Population structure of relict Metasequoia glyptostroboides and its habitat fragmentation and degradation in south-central China. - Biological Conservation 144: 279-289. 


$$
-6064 \text { - }
$$

[32] Tzedakis, P. C., Lawson, I. T., Frogley, M. R., Hewitt, G. M., Preece, R. C. (2002): Buffered tree population changes in a Quaternary refugium: evolutionary implications. Science 297: 2044-2047.

[33] Wei, X. Z., Jiang, M. Z., Huang, H. D., Yang, J. Y., Yu, J. (2010): Relationships between environment and mountain riparian plant communities associated with two rare tertiaryrelict tree species, Euptelea pleiospermum (Eupteleaceae) and Cercidiphyllum japonicum (Cercidiphyllaceae). - Flora 205: 841-852.

[34] Wu, Z. Y. (1991): The areal types of genera of Chinese seed plants. - Acta Botanica Yunnanica supplementary IV: 1-139. (in Chinese with English abstract).

[35] Wu, H., Meng, H. J., Wang, S. T., Wei, X. Z., Jiang, M. X. (2018): Geographic patterns and environmental drivers of seed traits of a relict tree species. - Forest Ecology and Management 422: 59-68.

[36] Xia, A. M. (2004): Studies on vertical distribution pattern of vegetation on the southern slope of western Mt. Tianmu, Zhejiang. - East China Normal University, Shanghai, Master paper, pp. 28-32. (in Chinese with English abstract).

[37] Zhang, F., Liang, H. W., Xiong, D. (2007): Study on the change of physiology and biochemistry during seed germination of Emmenopterys henryi Oliv. - Seed 26: 21-23. (in Chinese with English abstract).

[38] Zhang, Y. H., Wang, I. J., Comes, H. P., Peng, H., Qiu, Y. X. (2016): Contributions of historical and contemporary geographic and environmental factors to phylogeographic structure. - Scientific Reports 6: 24041. 


\section{APPENDIX}

Appendix A. Floristic composition and RBA (\%) of the woody plant in the sample plots

\begin{tabular}{|c|c|c|c|c|c|c|c|c|c|c|c|c|c|}
\hline \multirow{2}{*}{ Parameters } & \multirow{2}{*}{$\begin{array}{c}\text { Genus } \\
\text { distribution }\end{array}$} & \multicolumn{12}{|c|}{ Plot } \\
\hline & & $\mathbf{1}$ & 2 & 3 & 4 & 5 & 6 & 7 & 8 & 9 & 10 & 11 & 12 \\
\hline Microtopographic type & & \multicolumn{4}{|c|}{ Hollow head } & \multicolumn{4}{|c|}{ Flood terrace } & \multicolumn{4}{|c|}{ River bed } \\
\hline Plot area $\left(\mathrm{m}^{2}\right)$ & & 400 & 400 & 400 & 400 & 400 & 400 & 400 & 400 & 400 & 400 & 400 & 200 \\
\hline Number of plants & & 186 & 113 & 83 & 123 & 96 & 104 & 244 & 118 & 66 & 280 & 120 & 82 \\
\hline Maximum height (m) & & 35 & 35 & 15.5 & 30 & 24 & 36 & 13 & 18 & 32 & 9 & 15.5 & 16 \\
\hline Maximum DBH $(\mathrm{cm})$ & & 101 & 69 & 40.8 & 129 & 109 & 81 & 18.5 & 28.5 & 100 & 18 & 59.3 & 65.8 \\
\hline Average DBH & & 4.2 & 5 & 6.9 & 7.2 & 6.2 & 5 & 5.9 & 6.5 & 5.7 & 3.3 & 7.4 & 6.3 \\
\hline Average Height & & 5 & 7 & 10.3 & 7.8 & 8.5 & 6.9 & 5.6 & 6.2 & 8 & 3.4 & 11.8 & 7.8 \\
\hline Total basal area $\left(\mathrm{m}^{2} / 100 \mathrm{~m}^{2} \mathrm{plot}\right)$ & & 4037 & 5154 & 2497 & 6129 & 5023 & 3465 & 2383 & 1944 & 4005 & 1387 & 2088 & 4330 \\
\hline $\begin{array}{c}\text { Deciduous Coniferous Tree } \\
\text { Pseudolarix amabilis } \\
\text { Deciduous Broadleaved Tree }\end{array}$ & China & $47.3 *$ & $18.1^{*}$ & & & & $37.2 *$ & & & & & & \\
\hline Emmenopterys henryi & China & $15.5^{*}$ & $35.3^{*}$ & $67.6^{*}$ & $15.2 *$ & $23.7 *$ & $33.7 *$ & $40.2 *$ & $57.2 *$ & $41.9^{*}$ & $70.7 *$ & $86.9^{*}$ & $97.0^{*}$ \\
\hline Bothrocaryum controversum & NTem & & 0.1 & $8.2 *$ & $<0.1$ & & 0.7 & 5.4 & & 0.4 & $14.7 *$ & 4.1 & 0.1 \\
\hline Acer henryi & NTem & & & 0.1 & $<0.1$ & & 0.4 & & & 0.1 & $<0.1$ & $<0.1$ & $<0.1$ \\
\hline Acer mono & NTem & & & & $<0.1$ & & & & & 0.2 & $<0.1$ & 0.3 & 0.4 \\
\hline Cyclocarya paliurus & China & 7.8 & 1.9 & $<0.1$ & 3.3 & & 1.1 & 5.1 & $13.9 *$ & & & & \\
\hline Quercus aliena var. acutiserrata & NTem & & 5.4 & & & & 0.9 & & & & & & \\
\hline Toxicodendron vernicifluum & EAs,NAm,dis & & & 5.0 & 0.3 & 4.8 & & & 1.1 & & & & \\
\hline Kalopanax septemlobus & EAs & & 2.4 & & & & & & & & & & $<0.1$ \\
\hline Liquidambar acalycina & EAs,NAm,dis & 1.4 & $17.1^{*}$ & & & & & & & & & & \\
\hline Padus obtusata & NTem & & 4.4 & 4.2 & & & & & & & & & \\
\hline Ilex macropoda & PanTr & & & 0.1 & & & & & & & & & \\
\hline Acanthopanax evodiaefolius & EAs & & & & $<0.1$ & & & & & & & & \\
\hline Acer palmatum & NTem & & $<0.1$ & 3.6 & & & & & & & & & \\
\hline Acer olivaceum & NTem & & & & & $<0.1$ & 0.1 & & 0.7 & & & & \\
\hline Acer davidii & NTem & & & & & 0.2 & & & $<0.1$ & & & & \\
\hline Ehretia thyrsiflora & EAs & & & & & 6.2 & & 1.9 & 5.0 & & & & \\
\hline Juglans cathayensis var. formosana & NTem & & & & & & 2.2 & & & & & & \\
\hline
\end{tabular}

APPLIED ECOLOGY AND ENVIRONMENTAL RESEARCH 18(5):6053-6067.

http://www.aloki.hu • ISSN 15891623 (Print) • ISSN1785 0037 (Online)

DOI: http://dx.doi.org/10.15666/aeer/1805_60536067

(c) 2020, ALÖKI Kft., Budapest, Hungary 


\begin{tabular}{|c|c|c|c|c|c|c|c|c|c|c|c|c|c|}
\hline \multirow{2}{*}{ Parameters } & \multirow{2}{*}{$\begin{array}{c}\text { Genus } \\
\text { distribution }\end{array}$} & \multicolumn{12}{|c|}{ Plot } \\
\hline & & 1 & 2 & 3 & 4 & 5 & 6 & 7 & 8 & 9 & 10 & 11 & 12 \\
\hline Cladrastis wilsonii & EAs,NAm,dis & & & & & & $<0.1$ & & 4.2 & & & & \\
\hline Nyssa sinensis & EAs,NAm,dis & & & & & & 2.1 & & & & & & \\
\hline Fraxinus insularis & NTem & & & & & & & & 0.1 & & & & \\
\hline Celtis sinensis & PanTr & & & & & & 0.2 & & & & & & \\
\hline Celtis chekiangensis & PanTr & & & & & & 3.0 & & 4.7 & & & & \\
\hline Alangium chinense & Old World Tr & & & & & & 2.2 & & & 1.7 & 6.5 & & 0.7 \\
\hline Magnolia cylindrica & EAs,NAm,dis & & & & & & 2.0 & & & 1.1 & $<0.1$ & 6.2 & $<0.1$ \\
\hline Diospyros glaucifolia & PanTr & & & & & & & & & 1.0 & & & \\
\hline Pistacia chinensis & $\begin{array}{l}\text { Med to TrAs, } \\
\text { Aus.SAm,dis }\end{array}$ & & & & & & & 6.2 & & 0.3 & & & \\
\hline Deciduous Broadleaved Shrub & & & & & & & & & & & & & \\
\hline Lindera glauca & TrAs & 0.3 & 0.3 & & 0.9 & 0.6 & & 0.7 & & & & & 0.1 \\
\hline Symplocos paniculata & $\operatorname{Pan} T r$ & & $<0.1$ & & 0.1 & $<0.1$ & $<0.1$ & $<0.1$ & & $<0.1$ & 0.1 & & \\
\hline Hydrangea chinensis & EAs,NAm,dis & & $<0.1$ & & 0.1 & 0.2 & $<0.1$ & 0.1 & & $<0.1$ & 1.9 & & 0.1 \\
\hline Lonicera hemsleyana & NTem & & 0.1 & & 0.1 & & 0.2 & 1.1 & & & 0.1 & 0.1 & \\
\hline Lonicera modesta & NTem & & & $<0.1$ & $<0.1$ & $<0.1$ & $<0.1$ & $<0.1$ & & & & & \\
\hline Euonymus hamiltonianus & NTem & & $<0.1$ & & 0.1 & & & $<0.1$ & 0.1 & & & & \\
\hline $\begin{array}{c}\text { Dendrobenthamia japonica var. } \\
\text { chinensis }\end{array}$ & EAs & 2.1 & 0.9 & & & & & 2.5 & 0.7 & & & & \\
\hline Mallotus japonicus var. floccosus & Old World Tr & & & & $<0.1$ & 0.1 & & 0.4 & 2.4 & & & & \\
\hline Lindera fruticosa & TrAs & & & & $<0.1$ & $<0.1$ & & & & & & & \\
\hline Meliosma flexuosa & TrAs,TrAm,dis & & $<0.1$ & & & 0.1 & & 0.1 & $<0.1$ & & & & \\
\hline Meliosma oldhamii & TrAs,TrAm,dis & 0.1 & & $9.3 *$ & 0.1 & 0.2 & & $<0.1$ & 7.8 & & & & \\
\hline Clerodendrum trichotomum & PanTr & & & & & $<0.1$ & & $<0.1$ & & & & & \\
\hline Callicarpa giraldii & PanTr & $<0.1$ & & 0.5 & 0.2 & 0.1 & 0.2 & 0.1 & 0.4 & & & & \\
\hline Styrax obassia & $\operatorname{PanTr}$ & & & & 0.2 & & & & & & & & \\
\hline Corylopsis glandulifera & EAs & $<0.1$ & $<0.1$ & & & & & & & & & & \\
\hline Viburnum dilatatum & NTem & $<0.1$ & 0.1 & $<0.1$ & $<0.1$ & & & & & & & & \\
\hline Viburnum erosum & NTem & & & & & & & & 0.6 & & & & \\
\hline Rhamnus utilis & $\mathrm{Cos}$ & & & & & $<0.1$ & $<0.1$ & $<0.1$ & 0.3 & & & & \\
\hline Rhamnus globosa & $\mathrm{Cos}$ & & & & & $<0.1$ & $<0.1$ & $<0.1$ & 0.6 & & & & \\
\hline
\end{tabular}




\begin{tabular}{|c|c|c|c|c|c|c|c|c|c|c|c|c|c|}
\hline \multirow{2}{*}{ Parameters } & \multirow{2}{*}{$\begin{array}{c}\text { Genus } \\
\text { distribution }\end{array}$} & \multicolumn{12}{|c|}{ Plot } \\
\hline & & 1 & 2 & 3 & 4 & 5 & 6 & 7 & 8 & 9 & 10 & 11 & 12 \\
\hline Photinia beauverdiana & EAs,NAm,dis & & & & & $<0.1$ & 0.5 & & & & & & \\
\hline Meliosma veitchiorum & TrAs,TrAm, dis & & & & & 0.4 & & & & & & & \\
\hline Styrax confusus & $\operatorname{PanTr}$ & & & & & $<0.1$ & & & & & & & \\
\hline Aralia chinensis & EAs,NAm,dis & & & & & $<0.1$ & 0.1 & & & 0.1 & & & \\
\hline Viburnum plicatum var. tomentosum & NTem & & & & & 0.2 & 0.1 & $<0.1$ & & $<0.1$ & & 0.4 & \\
\hline Sambucus williamsii & NTem,STem, dis & & & & & $<0.1$ & $<0.1$ & & & 0.3 & & & $<0.1$ \\
\hline Phyllanthus glaucus & $\operatorname{PanTr}$ & & & & & $<0.1$ & $<0.1$ & & & 0.1 & 2.0 & & $<0.1$ \\
\hline Lindera praecox & TrAs & & & & & $<0.1$ & 0.1 & 3.0 & & & & & 0.1 \\
\hline Deutzia glauca & EAs & & & & & $<0.1$ & $<0.1$ & 0.1 & & & $<0.1$ & & \\
\hline Picrasma quassioides & TrAs \& Tr Am dis & & & & & & & & & $<0.1$ & & & \\
\hline Stewartia gemmata & EAs,NAm,dis & & & 0.2 & & & & & & 1.0 & 2.7 & 0.8 & \\
\hline Stachyurus chinensis & EAs & & & & & & & & & 0.1 & 1.2 & 0.1 & \\
\hline Evergreen Coniferous Tree & & & & & & & & & & & & & \\
\hline Cryptomeria fortunei & EAs & $16.7 *$ & 0.3 & & $61.3^{*}$ & $53.4 *$ & 0.3 & & & $49.1 *$ & & & \\
\hline Cunninghamia lanceolata & China & 0.1 & 0.6 & & $11.6^{*}$ & 3.8 & $<0.1$ & $17.0^{*}$ & & 1.4 & & & \\
\hline Evergreen Broad-leaved Tree & & & & & & & & & & & & & \\
\hline Lithocarpus harlandii & EAs & 1.0 & 2.7 & & 5.5 & 5.4 & 5.5 & $15.8^{*}$ & & 0.8 & $<0.1$ & 0.9 & 0.7 \\
\hline Cyclobalanopsis gracilis & NTem & $<0.1$ & & & & & 1.1 & & & & & & \\
\hline Litsea coreana var. sinensis & TrAs,TrAm,dis & & & 1.2 & $<0.1$ & $<0.1$ & & & 0.1 & & & & \\
\hline Cyclobalanopsis myrsinifolia & NTem & 0.1 & $8.4^{*}$ & $<0.1$ & 0.6 & $<0.1$ & 0.1 & & $<0.1$ & & & & \\
\hline Evergreen Broad-leaved Shrub & & & & & & & & & & & & & \\
\hline Daphniphyllum macropodum & TrAs to $\operatorname{Tr}$ Af & 7.6 & 1.8 & & 0.2 & 0.4 & 5.9 & & & 0.4 & & & 0.5 \\
\hline Elaeagnus pungens & NTem & & $<0.1$ & & $<0.1$ & & $<0.1$ & 0.4 & & & & & \\
\hline Orixa japonica & EAs & & & & 0.1 & & $<0.1$ & & & & & & \\
\hline Eurya hebeclados & TrAs, TrAm, dis & & & & & & & & 0.1 & & & & \\
\hline Pittosporum illicioides & Old World Tr & & & & & & & & & & & & 0.2 \\
\hline
\end{tabular}

Note: RBA-relative percent of basal area. Dominant species of each stands are indicated by an asterisk. E-East, N-North, S-South, As-Asia, Tem-Temperate, Cos-

Cosmpolitan, Aus-Australasia, Tr-Tropic, Am-America, Med-Mediterranea, dis-disjuncted (Wu, 1991). Dominant species are indicted by an asterisk 